\title{
Introduction to the 5th focus-on issue devoted to disaster and military surgery
}

\author{
F. Turégano $\cdot$ S. Lennquist
}

Received: 11 June 2014 / Accepted: 20 June 2014/Published online: 26 July 2014

(c) Springer-Verlag Berlin Heidelberg 2014

The fifth Focus-On Issue devoted to Disaster and Military Surgery in this journal is dedicated to several different fields within this topic. The first two papers deal with educational and training issues. One of them describes current challenges in the training of military surgeons, and reports the experience from Dutch combat operations in Afghanistan [1]. The surgical workload is compared to that of the surgical residents and the pre-deployment medical specialist program. Their findings are interesting, and the authors call into question the current civilian resident training, which is far away from the competencies of a fully trained military surgeon. They recommend the recognition of military surgery as a subspecialty within general (trauma) surgery in the Netherlands, and also the introduction of a NATO Military (and Disaster) surgery standard.

The paper by K. Lennquist et al. [2] reports on the development and evaluation of a new simulation model for interactive training of the medical response to major incidents and disasters (the MRMI courses organized under the auspices of ESTES). It is well known that this model is based on simulation cards whose accuracy was evaluated as very good or good by almost all participants, and so was also the extent to which the course increased their competencies to respond to major incidents and disasters. The simulation system is very well described, together with the different components of the course.

F. Turégano $(\bowtie)$

Gregorio Marañón Hospital, Madrid, Spain

e-mail: fturegano.hgugm@salud.madrid.org

S. Lennquist

Linköping, Sweden
The next two papers deal with clinical issues in the hospital management of casualties from terrorist explosions. I. Ashkenazi et al. [3] describe pitfalls to avoid, based on their extensive experience. They remind us that primary triage is inaccurate in identifying all critically injured, and that this primary triage should be corroborated by repeated detailed examinations. In their series, over $40 \%$ of operations were considered either immediate, urgent or high priority. An interesting recommendation, although difficult to follow in many countries, is that postmortem CT or formal autopsy should be mandatory for those dead on or immediately after arrival if we wish to improve survival in the prehospital setting.

The second manuscript on this topic is a review on abdominal blast injuries, and the different severity and prognosis in relation to the main mechanism of injury [4]. The review focuses in part on a collaborative study gathering the experience from the Madrid terrorist explosions of 2004, and the experience of the authors of the previous paper. It shows that primary and tertiary blast injuries have predominated in survivors from explosions in enclosed spaces reported outside of Israel; on the contrary, secondary blast injuries causing fragmentation wounds were predominant in suicide bombings in open and/or semiconfined spaces, mainly in Israel, and also in military conflicts, and carried the highest anatomic severity and mortality rate. Most deaths assessed occurred early, with hemorrhagic shock from penetrating fragments as the main contributing factor.

The paper by K. Mattox is a thorough and comprehensive review of fluid resuscitation in trauma [5]. It has the additional value of having been written by a world authority on the subject, and reflects on the sequential and evolutionary changes in our concepts of resuscitation, crystalloids, blood and blood products administration, level 
of blood pressure in hypotensive post traumatic patients, and outcome in such patients. He finally addresses the current standards, best practices and concerns relating to post traumatic fluid resuscitation.

In a review with the title "Wounds of war in the civilian sector-principles of treatment and pitfalls to avoid", Louis Riddez, based on extensive experience in serving as a surgeon in poor countries hit by armed conflicts and disasters, emphasizes the differences in treatment under these circumstances and with these mechanisms of injury as compared to treatment of civilians under optimal conditions [6]. The description of the principles is very basic, but on the other hand recent experiences from armed conflicts and disasters repeatedly show that knowledge of these principles is mandatory for surgeons going on missions in such areas, and never can be emphasized enough. The description of pitfalls to avoid is an important reminder for everyone taking the challenge to serve under these circumstances.

The last paper is a review of the second edition of the book on "War Surgery" edited by Husum et al. and already recognized as an important contribution to this field [7]. Several improvements based on the experiences from the first edition have made this book even better. The six sections of the book are reviewed in detail, highlighting several merits such as the guidelines and recommendations for preparedness, training and performance for those who have to take care of war wounds with very limited resources; also, the models described using anesthetized animals (pigs) for training of resuscitation and basic primary surgery not only for medical staff, but also for nonmedical professionals that have to take primary care of wounded without access to professional staff.

In all, this focus-on issue devoted to the field of disasters and military surgery covers several topics encompassing training, clinical care and others, together with reviews which should help the reader in gaining perspective of where this discipline stands nowadays, and where it is headed to.

Conflict of interest F. Turégano and S. Lennquist declare that there is no conflict of interest.

\section{References}

1. Hoencamp R, Tan ECTH, Idenburg F, Ramasamy A, van Egmond T, Leenen LPH, Hamming JF. Challenges in training of military surgeons: experiences from Dutch combat operations in Southern Afghanistan. Eur J Trauma Emerg Surg 2014. doi:10.1007/s00068014-0401-z.

2. Lennquist Montán K, Hreckovski B, Dobson B, Örtenwall P, Montán C, Khorram-Manesh A, Lennquist S. Development and evaluation of a new simulation model for interactive training of the medical response to major incidents and disasters. Eur J Trauma Emerg Surg 2013. doi:10.1007/s00068-013-0350-y.

3. Ashkenazi I, Turégano-Fuentes F, Einav S, Kessel B, Alfici R, Olsha O. Pitfalls to avoid in the medical management of mass casualty incidents following terrorist bombings: the hospital perspective. Eur J Trauma Emerg Surg 2014. doi:10.1007/ s00068-014-0403-x.

4. Turégano-Fuentes F, Pérez-Diaz D, Sanz-Sánchez M, Alfici R, Ashkenazi I. Abdominal blast injuries: different patterns, severity, management, and prognosis according to the main mechanism of injury. Eur J Trauma Emerg Surg 2014. doi:10.1007/s00068-0140397-4.

5. Mattox K. The ebb and flow of fluid (as in resuscitation). Eur J Trauma Emerg Surg 2014. doi:10.1007/s00068-014-0437-0.

6. Riddez L. Wounds of war in the civilian sector-principles of treatment and pitfalls to avoid. Eur J Trauma Emerg Surg 2014. doi:10.1007/s00068-014-0395-6.

7. Lennquist S. Husum H, Ang SC, Fosse E, editors. War Surgery, 2nd Edition. Trauma Care Foundation, University Hospital North, Norway 2011. ISBN 978-983-2729-21-1. Eur J Trauma Emerg Surg 2014. doi:10.1007/s00068-014-0402-y. 